\title{
ARTÍCULO
}

\section{Igualdad y no discriminación en tiempo de pandemia ${ }^{1}$}

\section{Equality and non-discrimination in pandemic times}

\author{
María Ángeles (Maggy) Barrère Unzueta. Facultad de Derecho. Universidad del País Vasco \\ (UPV/EHU). \\ Andrés Gascón Cuenca. Instituto de Derechos Humanos. Universitat de València. \\ Agustina Palacios. CONICET. Centro de Investigación y Docencia en Derechos Humanos Alicia \\ Moreau. Universidad Nacional de Mar del Plata. Argentina. \\ Paulina Ramírez Carvajal. Facultad de Derecho. Universidad de Alcalá.
}

Fecha de recepción 28/12/2010 | De aceptación: 01/05/2021 | De publicación: 24/06/2021

\section{RESUMEN,}

El presente trabajo realiza un análisis de cuál ha sido el impacto que el SARS-Cov-2 ha tenido en diversos grupos sociales, desde el prisma de la confrontación de los determinantes sociales y legales de la salud. En el texto se argumenta la visión crítica que se debe afrontar frente a la utilización de los últimos por suponer la invisibilización de patrones subordiscriminatorios dentro del contexto social actual.

\section{PALABRAS CLAVE.}

SARS-Cov-2; subordiscriminación; determinantes legales; determinantes sociales; derecho a la salud.

\section{ABSTRACT.}

This article analyses the impact that SARS-Cov-2 has had on various social groups, by confronting of the social and legal determinants of health. The text argues that a critical view that must be hold in the use of the latter, as it disregards subordinate patterns of discrimination within the current social context.

\section{KEY WORDS.}

SARS-Cov-2; discrimination; legal determinants; social determinants; right to health.

\footnotetext{
${ }^{1}$ Este trabajo es uno de los resultados del proyecto de investigación «Determinantes Legales y Éticos del COVID-19», financiado por el Vicerrectorado de Investigación y Transferencias de la Universidad de Alcalá (COVID-19 UAH 2019/00003/016/001/017).
} 
Sumario: 1. Introducción; 2. El SC-2 en contexto sistémico e interseccional; 3. La teoría de los determinantes sociales de la salud y el derecho a la salud; 3.1. Teorización y definición de la OMS; 3.2. Proyección sobre el derecho a la salud; 4. La tutela antidiscriminatoria en el derecho a la salud; 4.1. La igualdad sustantiva como corrección al falso universalismo; 4.2. El concepto jurídico de discriminación; 4.3. La introducción de la discriminación estructural, sistémica, o subordiscriminación; 5. Consideraciones conclusivas.

\section{Introducción}

La pandemia causada por el virus SARS-Cov-2 (en adelante SC-2) ha conllevado una "situación de emergencia social sin precedentes" (Almirón, 2020) de cuyo crecimiento diario y sucesivas "olas" dan fe los datos que se van conociendo en todo el mundo. Los estudios insisten en que "el virus no discrimina" (Oxfam, 2020), y se dice con razón, siempre que se aclare el uso que se hace en este caso del verbo discriminar. Porque diferenciar es la primera acepción del verbo discriminar y el SC-2 sí parece que tiene efectos diferentes según las personas a las que infecta. Conviene aclarar por tanto que, cuando se dice que el SC-2 (como cualquier otro virus) no discrimina, lo que se quiere decir es que, aunque es muy posible que su salto a la especie humana no haya sido estrictamente causal, y que afecte de manera diferente a unas personas y a otras por motivos biológicos (como la edad), el virus, como tal, no es un producto humano, carece de intencionalidad y, por tanto, no admite condenas morales ni exigencia de responsabilidades. Dicho de otro modo, los efectos diferentes que su infectividad produce entre las personas, o entre los grupos sociales, no responden a una conducta que pueda romper con la regla de justicia de tratar igual a los iguales y desigual a los desiguales (concepto clásico de la discriminación en la cultura jurídica). En este sentido, solo metafóricamente (atribuyendo al virus capacidades antropomórficas) se puede decir que el virus "trata" o "se comporta" (bien o mal, de manera justa o injusta).

Que el virus no se comporte ni trate de una determinada forma y, por lo tanto, no pueda discriminar, no quiere decir que infecte o se expanda aleatoriamente. Es palmario que el SC-2 está teniendo un mayor impacto en determinados grupos sociales, lo que permite afirmar que "el virus viene con las cartas marcadas" (Madrid, 2020). Un marcaje que se produce por (y se significa en) sistemas de poder que sí dependen, al menos en gran medida, de la acción humana que precipita en recortes sanitarios, escasez de personal en las residencias de mayores, hacinamiento en las viviendas de ciertos barrios, feminización e infravaloración de las profesiones vinculadas al cuidado, etc. (Rendueles, 2020: 350). 
Este tipo de conductas de dimensiones sistémicas y que en la pandemia han tenido consecuencias graves en la salud de las personas (cuando no mortales), pasan, sin embargo, desapercibidas para el concepto clásico de discriminación utilizado tradicionalmente por el Derecho antidiscriminatorio, contribuyendo así a su reproducción.

Con esta tesis de fondo, el trabajo se estructurará de la siguiente manera. Tras esta introducción, en el apartado segundo, se hará una breve recopilación de datos aparecidos en noticias, estudios e informes que ilustran el impacto directo del SC-2 en la salud de las personas. Este detalle es importante porque delimita el objeto de análisis del trabajo. Así, en este no se trata de examinar la repercusión de las normativas y medidas adoptadas con ocasión de la pandemia (por ejemplo, de lo que está suponiendo el confinamiento, o el uso de las mascarillas, o el teletrabajo, o la enseñanza telemática, o los ERTES, o el IMV, etc.), sino el impacto del virus (es decir, la infección y la enfermedad) independientemente incluso de tales medidas y normativas. La idea fundamental es subrayar que lo que realmente discrimina son los (tratos insertos y significados en) sistemas de poder como la clase, el género, la etnia, ser migrante, ser una persona con discapacidad, etc., que configuran la realidad sobre la que incide el virus.

En el tercer apartado, se abordará la teoría de los determinantes sociales de la salud elaborada por la OMS y su recepción doctrinal a la hora de conceptualizar el derecho a la salud sin discriminación, destacándose la importancia de este planteamiento a la vez que alguna eventual duda interpretativa referida al contexto de expansión del virus. En el cuarto apartado, se analizará la tutela antidiscriminatoria prevista en las leyes a la hora de garantizar el derecho a la salud sin discriminación en la época de pandemia ocasionada por el SC-2, cuestionando su virtualidad, y proponiéndose un esquema que, fundado en el principio de igualdad sustantiva, incluya el concepto de discriminación estructural, sistémica o subordiscriminación (Barrère, 2019). El trabajo finalizará con un apartado dedicado a recoger algunas consideraciones conclusivas.

\section{EI SC-2 en contexto sistémico e interseccional}

Los efectos amplificadores de la pandemia sobre la desigualdad sistémica (por clase, género, etnia, migración, discapacidad, etc.) e interseccional han sido suficientemente ilustrados por los estudios elaborados en los meses transcurridos desde su inicio. De ellos se destacarán algunos con datos de la 
realidad española, pero que se suponen extrapolables a otros países. Su exposición se agrupará por categorías sistémicas, que, si bien se presentan a continuación de manera estanca, deben ser interpretadas desde una perspectiva interseccional, que abarque la interacción entre sistemas de opresión, desde el entendimiento de que las identidades y las posiciones sociales no se encuentran conformadas por una categoría sino por varias que interaccionan (Barrère, 2016).

\section{A) La clase social}

Como apuntan Padilla y Gullón (2020), en las epidemias lo que se transmite no son solo los virus y las bacterias, pues, a pesar de la creencia de que los mecanismos de contagio se distribuyen de forma aséptica sin atender a consideraciones de clase social, grupo étnico o demarcación territorial, lo cierto es que las epidemias entienden de clases sociales mucho más de lo que lo hacen la mayoría de los seres humanos. De esta forma se refleja en los estudios mencionados a continuación.

Con fecha 16 de abril de 2020 la Fundación IO, una organización científica, de naturaleza fundacional, independiente, informó de los resultados de su encuesta virtual en el marco del proyecto COVID TREND19, tomando como ejemplo el barrio de Vallecas (Madrid). Los datos preliminares muestran que hay una relación directa entre el nivel de renta, la superficie de vivienda y la afectación del coronavirus. Además de las dimensiones de la vivienda, se apunta a otros factores que influirían en el aumento de contagios en esta zona de Madrid, como el gran porcentaje de población institucionalizada (al no disponer de recursos económicos para tener una persona a cargo de su cuidado diario en el domicilio). Todo ello explicaría el mayor número de contactos por persona/día en las primeras fases de la epidemia, previas a la instauración de las medidas de confinamiento establecidas por el Gobierno. Los resultados del estudio también apuntan a que esta correlación existe en todo el Estado².

En la misma línea, con fecha 10 de agosto de 2020 se publicó otro estudio en la Journal of Public Health liderado por investigadores/as del Instituto Hospital del Mar de Investigaciones Médicas (IMIM) y el IDIAPJGol ${ }^{3}$. Los datos obtenidos de la investigación revelan que, en Barcelona, el distrito con la media de renta más baja, Nou Barris, registró durante el pico de la epidemia una incidencia de

\footnotetext{
${ }^{2}$ Herramienta COVID TREND de la Fundación IO: http://old.com.fundacionio.es/2020/04/16/covid19-la-enfermedad-si-entiende-declases-nuestros-datos-en-vallecas-madrid/; https://www.datoscovid.es/pages/fundacion-io (Acceso 4 de junio de 2021).

${ }^{3}$ Jose Miguel Baena-Díez, María Barroso, Sara Isabel Cordeiro-Coelho, Jorge L Díaz, María Grau, (2020) Impact of COVID-19 outbreak by income: hitting hardest the most deprived, Journal of Public Health, fdaa136.
} 
casos 2,5 veces más alta que el distrito con la renta más alta, Sarrià-Sant Gervasi. Los resultados destacan una relación directa entre una renta más baja y un número más alto de casos de COVID-19. Los distritos de la zona norte de Barcelona (Nou Barris y Horta Guinardó), que son los de menos ingresos de la ciudad, registraron la incidencia más alta de casos de COVID-19. Por el contrario, los distritos con más renta (Sarrià-Sant Gervasi y Les Corts), estuvieron entre los menos afectados. Las conclusiones del estudio son rotundas: las personas con menor nivel socioeconómico están sufriendo más la enfermedad. La diferencia en la incidencia del virus entre el distrito de menos ingresos y el de mayor renta determina un vínculo claro entre la vivienda y la incidencia de la enfermedad, con mayores datos cuando se constatan condiciones de habitabilidad peores, viviendas sobreocupadas o compartidas en los distritos más afectados.

Más recientemente, el 6 de octubre de 2020 se ha publicado en la revista Plos One una investigación elaborada por el Instituto de Salud Global de Barcelona (ISGlobal) junto a la City University of New York Graduate School of Public Health (CUNY SPH) y otras instituciones ${ }^{4}$. Los resultados del estudio señalan que las medidas de control de enfermedades se ven desafiadas por los riesgos y las cargas desiguales de la COVID-19, así como por el acceso a los recursos para prevenir la propagación de la enfermedad. Por ejemplo, las familias que no tienen agua corriente no pueden lavarse las manos; las personas sin hogar no pueden refugiarse en un lugar concreto; las que están en prisiones y en barrios marginales urbanos de alta densidad no pueden distanciarse físicamente; y el hacinamiento en los centros de acogida y detención aumenta la exposición de personas migrantes y refugiadas a la enfermedad.

Los estudios ${ }^{5}$ son pues unánimes en sus conclusiones: un nivel socioeconómico bajo, con nulos o escasos ingresos, implica vivir con unas condiciones (vivienda, cuidados, etc.) en las que se comprueba

\footnotetext{
${ }^{4}$ Lazarus J.V., et al., 2020.

${ }^{5}$ Las conclusiones aquí reflejadas son confirmadas por otros informes que también estudian esta situación, pero que, por razones de espacio, no pueden ser desarrollados de forma extensiva en este trabajo. En este sentido, el IEB Report 4/2020 del Institut d'Economia de Barcelona y el informe Distancia Social y Derecho al Cuidado de la Fundación Foessa reafirman las conclusiones de las investigaciones previas, a saber, la pandemia ha tenido un impacto desproporcionadamente mayor en los grupos sociales en mayor riesgo de exclusión. Ver: Bosch, 2020 y Foessa 2020. Además, esta realidad se ha reflejado en otros Estados como demuestran otras investigaciones. En este sentido ver: Chen y Krieger, 2021.
} 
una mayor incidencia del virus ${ }^{6}$. Las epidemias y las pandemias, por tanto, raramente afectan a toda la población de la misma forma (Padilla y Gullón 2020).

\section{B) El género}

En lo que respecta al género, resulta significativa la mayor incidencia de la COVID-19 en las mujeres y el impacto social específico que ha supuesto la pandemia en ellas (Wenham et al 2020). Aquí se tomarán en cuenta tres actividades en las que la incidencia del SC-2 les afecta particularmente: la del cuidado, la realizada en el hogar y la de prostitución ${ }^{7}$.

Sobre la primera, es necesario destacar que en España más del 75\% de las personas que realizan labores de cuidado a personas en situación de dependencia son mujeres (Del Río-Lozano et al, 2020) ${ }^{8}$. Como apunta Ruiz Cantero (2020), debido a que el rol de cuidados se considera antecedente epidemiológico de riesgo, es posible saber que en España existen significativamente más casos confirmados en mujeres que en hombres con contacto estrecho con casos de COVID-19 probable o confirmada, o contacto con personas con infección respiratoria aguda, que también podrían ser debidos a la COVID-19, no diagnosticados. En cuanto al personal sanitario, mayormente feminizado, en mayo de 2020, el 76\% de los casos de COVID-19 afectaban a mujeres, estando además sobrerrepresentadas en todos los grupos de edad, excepto en el grupo de mayores de 65 años. A 28 de octubre de 2020, el número de mujeres con inicio de síntomas o diagnóstico era 3,55 veces más que el de hombres ${ }^{9}$.

\footnotetext{
${ }^{6}$ Todo ello -se insiste- sin entrar en el análisis de las medidas políticas contra la pandemia, como el fomento del teletrabajo, ya que los estudios también demuestran que la población con un nivel socioeconómico bajo tiene mayor exposición al virus debido a que sus trabajos son presenciales y, además, utilizan el transporte público. Si de lo que se trata es de analizar la repercusión de la crisis sobre los considerados colectivos en exclusión social (trabajadoras sexuales, población migrante, personas sin hogar, población solicitante de asilo y refugio, personas con el VIH, colectivos LGTBIQ, personas usuarias de drogas y quienes están privadas de libertad), existe coincidencia en que las personas más afectadas por la crisis de la Covid-19 son las trabajadoras sexuales y la población migrante. Trabajando en positivo: Informe sobre el impacto de la Covid-19 en colectivos en exclusión social y sus necesidades prioritarias http://www.trabajandoenpositivo.org/documentos/informe_necesidadesycolectivos_covid19.pdf (Acceso 5 de junio de 2021).

${ }^{7}$ El impacto de la pandemia en las mujeres también se ha reflejado en otra problemática, en la violencia hacia las mujeres y las medidas que, en este contexto de crisis sanitaria, se han adoptado para su contención. En este sentido ver: Ruiz-Pérez y Pastor-Moreno, 2020.

${ }^{8}$ Cabe subrayar que más de 7,7 millones de europeas "no trabajan" para hacerse cargo de familiares frente a casi medio millón de hombres. Desde el Lobby Europeo de Mujeres se denuncia que el dinero y el esfuerzo que se emplea en cuidar "es invisible porque no está traducido en términos económicos" (el Eurostat no lo recopila) y, según el cálculo de la socióloga Ma Ángeles Durán, la ocupación del cuidado, que descansa normalmente sobre las espaldas de mujeres que atienden a familiares enfermos o menores, equivaldría a 28 millones de empleos. El País, 12 de octubre de 2020. 
En relación al trabajo doméstico, según datos de la $\mathrm{EPA}^{10}$, el número de personas en el empleo del hogar en España se acerca a las 600.000, siendo de ellas en torno al 96\% mujeres y la mitad personas migrantes. De esos cientos de miles están afiliadas a la Seguridad Social el 67\%. El resto (es decir, un $33 \%$ ) no tiene contrato y la mayoría son población migrante en situación administrativa irregular. A ello hay que añadir que, incluso quienes tienen contrato, carecen de prestación por desempleo, funcionando además la cláusula por desistimiento, es decir que se pueden ver en la calle de un día a otros sin justificación. En estas condiciones, cuando con ocasión de la pandemia, bien por miedo al contagio, bien por el relevo de sus tareas por la parte contratante confinada, su actividad se considera prescindible, su situación de desamparo es total.

En tercer lugar, procede mencionar la realidad de las mujeres que ejercen la prostitución. De acuerdo con ONUSIDA ${ }^{11}$ y Trabajando en Positivo ${ }^{12}$ este es uno de los colectivos que más está sufriendo las consecuencias de la pandemia con una pérdida total de ingresos y un aumento de la discriminación y el acoso que ya venían padeciendo ${ }^{13}$.

\section{C) La discapacidad}

Son también numerosos los documentos procedentes de organismos y agencias internacionales que destacan las "cartas marcadas" que encuentran las personas con discapacidad frente al virus ${ }^{14}$. Así, en

10 https://www.lavanguardia.com/local/valencia/20200324/4882989730/trabajadoras-hogar-confinamiento-coronavirus-despido.html (Acceso 4 de junio de 2021).

${ }^{11}$ Ver nota de prensa de 8 de abril de 2020 ONUSIDA Las trabajadoras del sexuales no deben quedarse atrás en la respuesta ante el COVID-19 https://www.unaids.org/es/resources/presscentre/pressreleaseandstatementarchive/2020/april/20200408 sex-workers-covid-19 (Acceso 5 de junio de 2021).

12 Ver anotación al pie 6.

13 Ver también, en este mismo sentido, Sex workers must not be forgotten in the COVID-19 response: https://www.thelancet.com/action/showPdf?pii=S0140-6736\%2820\%2931033-3 (Acceso 5 de junio de 2021); COVID-19 responses must uphold and protect he rights sex of sex https://www.unaids.org/en/resources/presscentre/featurestories/2020/april/20200424 sex-work (Acceso 5 de junio de 2021); COVID-19 Prevention and Protecting Sex Workers: A Call to Action: https://link.springer.com/article/10.1007/s10508-020-01849-x (Acceso 5 de junio de 2021); La perspectiva de género, esencial en la respuesta a la COVID-19: https://www.inmujer.gob.es/diseno/novedades/IMPACTO DE GENERO DEL COVID 19 (uv).pdf (Acceso 5 de junio de 2021).

${ }^{14}$ Cabe señalar que varios de los problemas con los que se han encontrado las personas con discapacidad son extrapolables a las personas con enfermedades crónicas, que pueden o no tener un grado de discapacidad reconocido. Las personas con enfermedades crónicas también han visto trastocada su salud y la incidencia y las consecuencias del virus en ellas han sido elevadas. Las interrupciones en sus tratamientos, las cancelaciones de sus citas médicas y los retrasos en los diagnósticos debido al colapso del sistema sanitario son solo algunos de los problemas que ha dejado la crisis sanitaria. Ver: https://www.plataformadepacientes.org/sites/default/files/informe covid19 final web ok.pdf (Acceso 7 de junio de 2021); https://www.publico.es/sociedad/alla-covid-enfermedades-agravan-consultas-canceladas-retrasos-diagnosticos.html (Acceso 7 de junio de 2021). 
un informe sobre cómo responder a la COVID-19, la ONU recuerda que a las barreras que enfrentan a diario las personas con discapacidad -estigmatización, falta de acceso a bienes y servicios básicos, pobreza, invisibilidad y abandono o institucionalización-, se suman las nuevas generadas por la COVID-19, que llevan a que el colectivo de personas con discapacidad se encuentre entre los más afectados por esta crisis en cuanto a muertes (ONU, 2020). Por su parte, la Alianza Internacional de Discapacidad (IDA) también se ha pronunciado sobre diversos aspectos de lo que está suponiendo la COVID-19 en las personas con discapacidad (IDA, 2020). Entre ellos destaca el mayor riesgo que tienen algunas de contraer la enfermedad, ya sea como consecuencia de las barreras que enfrentan para acceder a la información preventiva y la higiene, como a la necesidad de contacto con el medio ambiente o con las personas de apoyo, sin olvidar las afecciones respiratorias que pueden afectar a algunas de ellas ${ }^{15}$.

En este mismo ámbito, y en el contexto de la pandemia, se vienen planteando serias preocupaciones sobre los impactos discriminatorios de los protocolos de triaje ${ }^{16}$ que reflejan criterios que implican la negación o la eliminación de la atención de las personas con discapacidad. Ejemplos lamentables se han dado en diversos países, como en España, mediante un protocolo sanitario que establecía la restricción del acceso al hospital a aquellas personas que, "aunque tengan infección respiratoria, no puedan ser independientes en sus movimientos o tengan alguna discapacidad intelectual"17. Dicha medida fue objeto de denuncia por parte del Comité Español de Representantes de Personas con Discapacidad (CERMI), dando origen a una respuesta por parte del Comité de Bioética de España, según la cual "resulta claro que la discapacidad de la persona enferma no puede ser nunca por sí misma un motivo que priorice la atención de quienes carecen de discapacidad. Ello vulneraría nuestro ordenamiento jurídico, concretamente la Convención sobre los Derechos de las Personas con Discapacidad, que exige garantizar el derecho a la vida y la atención sanitaria a las personas con

\footnotetext{
${ }^{15}$ IDA (2020), "Hacia una respuesta inclusiva de la discapacidad frente a la Covid-19: 10 recomendaciones de la Alianza Internacional de Discapacidad", 19 de marzo.

16 Triaje significa ordenar o clasificar a los pacientes para recibir tratamiento. Mediante el proceso de triaje se organiza el flujo de pacientes asegurando que los más urgentes sean atendidos antes.

${ }^{17}$ Protocolo sobre el que se dio marcha atrás en la Comunidad de Madrid como consecuencia de la denuncia pública realizada por el Comité sobre los Derechos de las Personas con Discapacidad (CERMI) https://www.cermi.es/es/actualidad/noticias/el-cermi-exige-queno-se-discrimine-por-raz\%C3\%B3n-de-discapacidad-en-los-protocolos (Acceso 6 de junio de 2021). El polémico documento de Madrid: los ancianos con discapacidad y síntomas no se derivarán al hospital. El Español. https://www.elespanol.com/espana/madrid/20200325/polemico-documento-madrid-ancianos-discapacidad-noderivaran/477453553 0.html (Acceso 6 de junio de 2021).
} 
discapacidad en igualdad de condiciones con todas las demás”. En esa misma respuesta, el Comité añade que ese modo de proceder lesionaría también "de forma más flagrante principios éticos elementales, pues supondría entender que la vida de las personas con discapacidad tiene menos calidad y por tanto merece menos la pena atenderla, lo que resulta no solo absolutamente incoherente con la visión de la discapacidad que hoy tiene la sociedad española [...], sino que supondría establecer una división entre vidas humanas en función de un supuesto valor de esas vidas arbitrariamente asignado o en función de su utilidad social"18.

\section{D) La migración}

El impacto inicial del SC-2 también se ha visto reflejado en la población migrante, y no únicamente en su acceso al sistema sanitario. Baste recordar aquí la difusión más o menos sutil de la idea de que las personas migrantes (fundamentalmente jornaleros/as del sector hortofrutícola) eran al inicio de la pandemia los responsables de la propagación del virus (Madrid, 2020), o los mensajes que señalaban directamente como culpables de la situación a las personas de ascendencia asiática, asociando falazmente la COVID-19 con una nacionalidad (Turner-Musa et al, 2020).

Respecto del binomio migración-acceso al sistema sanitario, si antes de la crisis sanitaria su acceso al sistema ya era difícil, la implantación de la modalidad telemática en muchos centros de atención primaria ha supuesto una barrera más para aquellas personas extranjeras que no accedían al sistema sanitario antes de la pandemia (Beaunoyer et al, 2020: 111; Vieira et al, 2020). La falta de personal preparado para atender telefónicamente e identificar y abordar situaciones de vulnerabilidad no solo ha generado dificultades en la comunicación para la atención sanitaria en general (Azarola et al, 2020; Kluge et al, 2020: 1237-9), sino que también ha creado una barrera en el diagnóstico y el seguimiento del SC-2, más aún cuando muchas de estas personas no disponen de herramientas digitales. Las personas migrantes han sido, pues, unas de las más discriminadas por la brecha digital que también ha afectado a las personas mayores y la infancia, las personas sin hogar y las personas con discapacidad (EAPN, 2020; Beaunoyer et al, 2020: 111).

\footnotetext{
18 Informe del Comité de Bioética de España sobre los Aspectos Bioéticos de la priorización de recursos sanitarios en el contexto de la crisis del coronavirus $(23 / 03 / 2020)$, p. 10
} 
Sin embargo, la principal barrera identificada ha sido la falta de una cobertura sanitaria universal efectiva, sobre todo en casos de personas extranjeras en situación de estancia temporal, en situación administrativa irregular y otras situaciones relacionadas con el estatus migratorio (Trabajando en Positivo, 2020; Médicos del Mundo, 2020). En este sentido, los organismos internacionales hicieron una llamada a implementar reformas que incluyesen a todas las personas en la cobertura sanitaria, independientemente de su situación administrativa, y algunos países así lo hicieron (Wang y Tang, 2020; Bodenmann et al, 2020). En España, sin embargo, a pesar del Real Decreto-ley 7/2018, de 27 de julio, sobre el acceso universal al Sistema Nacional de Salud y del documento "Intervención sanitaria en situaciones de riesgo para la salud pública”, aprobado por el Consejo Interterritorial del SNS el 18 de diciembre 2013, se han seguido produciendo trabas en el acceso a la asistencia sanitaria de personas migrantes (Yo sí sanidad universal 2019; Defensor del Pueblo, 2019; Azarola et al, 2020; Kluge et al, 2020; Rights International Spain, 2020).

Exceptuando lo anterior es necesario mencionar que en algunas comunidades autónomas sí se han aprobado normativas más inclusivas para hacer efectiva la cobertura sanitaria universal a todas las personas con independencia de la situación administrativa, o se han tomado medidas específicas para garantizar su acceso y, así, por ejemplo, a las personas que trabajan en el sector hortofrutícola se les ha facilitado un número identificativo para garantizar su acceso o seguimiento ${ }^{19}$. No obstante, a pesar de estas medidas, son muchas las personas en situación administrativa irregular que no han acudido a los servicios de salud durante la crisis sanitaria por el miedo de que el uso de estos servicios derivase en que se les iniciase un expediente de expulsión. De ahí que hayan surgido iniciativas entre el movimiento asociativo a favor de la regularización de la situación de todas las personas que viven en España y la petición de la paralización de las deportaciones (Azarola, et al, 2020; Rights International Spain, 2020). Esto es importante porque las repercusiones negativas de la pandemia en el estado de salud de las personas migrantes persisten aun después del levantamiento del Estado de Alarma. Por otro lado, en la Comunidad de Madrid la paralización de los procesos administrativos y judiciales que estaban pendientes ha derivado en la irregularidad sobrevenida de muchas de estas personas,

\footnotetext{
${ }^{19}$ Gobierno de Aragón. El Gobierno de Aragón dará de alta a todos los migrantes en el sistema sanitario de forma temporal hasta el 30 de mayo. Aragón Hoy [Internet] 2020 [citado el 23/11/2020]. Disponible en: http://www.aragonhoy.net/index.php/mod.noticias/mem.detalle/area.1050/id.258553 (Acceso 8 de junio de 2021); Gobierno de Navarra. El Gobierno de Navarra toma medidas para garantizar la capacidad de la red sanitaria y afrontar el coronavirus. Navarra.es [Internet] 2020 [citado el 23/11/2020]. Disponible en: https://www.navarra.es/es/noticias/2020/03/16/el-gobierno-de-navarra-toma-medidas-paragarantizar-la-capacidad-de-la-red-sanitaria-y-afrontar-el-coronavirus (Acceso 8 de junio de 2021).
} 
impidiéndoles acceder a los servicios sanitarios por la falta de renovación de su documentación y por la imposibilidad de formalizar trámites esenciales relacionados con sus procedimientos a través de la plataforma online de acceso a citas habilitada por la Administración correspondiente.

Los efectos de la pandemia en ciertos grupos van más allá de las repercusiones en el ejercicio de su derecho a la asistencia sanitaria, pues, al menos en el caso de las personas migrantes, el retraso o imposibilidad de acceso a la correspondiente documentación impide que puedan ejercer otros derechos como el derecho al trabajo. Sin embargo, el estado de salud es el más afectado puesto que, como se verá más adelante, los determinantes sociales subyacentes a las condiciones de salud que afectan a estas poblaciones las sitúan en una posición de vulnerabilidad frente al virus, habida cuenta de que estos determinantes incluyen, entre otros, el acceso a la atención médica, la inseguridad económica, las condiciones deficientes de vivienda y vecindario y la disponibilidad de recursos. La falta de estos disminuye la calidad de vida e influye negativamente en los resultados de salud de la población migrante (Turner-Musa et al 2020).

\section{E) El edadismo}

En el informe del Grupo de Trabajo COVID-19 y residencias, del Ministerio de Derechos Sociales, se señala que "el edadismo o discriminación por edad existe y tiene efectos negativos en la salud de las personas mayores y en la autopercepción de la persona mayor, provocando consecuencias sociales como la invisibilización de las personas mayores y efectos en la atención sanitaria, o generando actitudes negativas en la prestación de cuidados a largo plazo" ${ }^{20}$.

Respecto de la atención sanitaria dispensada en los hospitales públicos a las personas mayores, los medios de comunicación se hicieron eco de cómo en algunas comunidades autónomas el personal sanitario, ante la falta de camas en las Unidades de Cuidados Intensivos, decidía a quién se ingresaba y a quién no, utilizando la edad como el criterio director, lo que significaba priorizar a la persona más joven solo por razón de su edad, postergando (con consecuencias mortales) a las personas de mayor edad únicamente por esta razón, empleando criterios utilitaristas que reducen, si no desvanecen, la garantía de derechos fundamentales. El edadismo, interseccionado con un sistema económico que "ve a las personas de edad avanzada como una carga y una fuente de gasto y de colapso del sistema

${ }^{20}$ Ministerio de Derechos Sociales y Agenda 2030 (2020), Informe del Grupo de Trabajo COVID-19 y residencias, p. 42. 
sanitario" 21 , es lo que permite significar de discriminatorios a los tratos mencionados. Por lo demás, no todos los tratos discriminatorios son siempre tan evidentes. De hecho, también en el ámbito de la atención sanitaria han sido apuntados comportamientos discriminatorios más sutiles: "Si a una persona que está enferma la envías a un hospital que no tiene UCI, o a un anciano que vive solo en casa lo derivas a un centro sociosanitario o a un hospital de larga estancia, que por supuesto tampoco tiene cuidados intensivos... pues obviamente hay una selección previa"22.

El Informe del GTM sobre "El impacto de la COVID-19 en las personas mayores, con especial énfasis en las que viven en residencias" 23 señala que las personas mayores pueden acumular "capas de vulnerabilidad" en función de su situación socioeconómica y de las discapacidades que tengan. Las situaciones de vulnerabilidad de las personas mayores también deben ser observadas desde el enfoque de la interseccionalidad ya que la interacción de dos o más factores puede dar lugar a una discriminación diferente de la proveniente de la suma o combinación de ellos ${ }^{24}$.

\section{F) Sobre los tipos de vulnerabilidad}

A finales de octubre de 2020 se publicó el documento "Equidad en Salud y COVID-19. Análisis y propuestas para abordar la vulnerabilidad epidemiológica vinculada a las desigualdades sociales”, coordinado por la Subdirección General de Promoción, Prevención y Calidad de la Dirección General de Salud Pública dependiente del Ministerio de Sanidad. La conclusión del trabajo subraya que el impacto de la COVID-19 no está siendo igual para todas las personas y que, según los datos recabados, pueden identificarse tres tipos de vulnerabilidad interrelacionados. En primer lugar, la vulnerabilidad

\footnotetext{
${ }^{21}$ Según la psicóloga y profesora de ética Marije Goikoetxea, de quien es la cita recogida en el texto (El Diario Vasco, 11 de octubre de 2020), ver a las personas ancianas como una carga, fuente de gasto y colapso del sistema sanitario, no sólo es injusto, sino totalmente falso: "Su aportación a la sociedad, no ya sólo en valores, experiencia, etc., incluso económicamente, es mayor que el gasto que generan. Basta calcular lo que aportan a través del copago en las residencias y la creación de trabajo y negocio, así como su papel como cuidadores de otros mayores, de los nietos... El 80\% de los mayores de 65 años cuidan y no son cuidados, y antes de la pandemia el $24 \%$ de los abuelos y abuelas cuidaban de sus nietos al menos 7 horas al día". Sobre la discriminación por razón de edad en España, vid. https://www.65ymas.com/uploads/s1/29/59/14/informe-la-discriminacio-n-por-razo-n-de-edad-en-espan-a-helpage-espan-acompressed.pdf (Acceso 7 de junio de 2021).

${ }^{22}$ Ibídem.

${ }^{23}$ Informe del GTM (2020), "El impacto de la COVID-19 en las personas mayores, con especial énfasis en las que viven en residencias", p. 16.

${ }^{24}$ Cabe señalar que en este trabajo se ha puesto el foco en la problemática específica de las personas mayores en el contexto pandémico, no obstante, el impacto etario que ha tenido la pandemia y el confinamiento también se ha observado en la salud y bienestar de las personas menores de edad. Varios estudios señalan que los determinantes sociales de la salud de los y las menores empeoran a medida que el nivel socioeconómico de los padres y madres desciende. En este sentido ver: González-Rábago et al, 2021; Valero Alzaga et al, 2020.
} 
clínica, según la cual algunas características individuales, como la edad o algunos problemas de salud crónicos como hipertensión arterial, diabetes, enfermedades cardiovasculares, enfermedades pulmonares crónicas, cáncer, inmunodeficiencias, conllevan una mayor vulnerabilidad y una peor evolución ante la enfermedad por COVID-19. En segundo lugar, la vulnerabilidad social, que pone de manifiesto el peso de los determinantes sociales de la salud y que es el resultado de dinámicas sociales de no reconocimiento de plenos derechos e igualdad entre personas y colectivos con base en ejes de desigualdad, como la situación económica, el nivel educativo, la situación laboral, las condiciones laborales, el estatus migratorio, el género, la etnia, la diversidad sexual o la diversidad funcional, entre otros. Por último, la vulnerabilidad epidemiológica, entendida como un mayor riesgo epidemiológico por una mayor exposición a la infección, retraso en el diagnóstico e identificación de contactos o mayor dificultad para seguir las medidas de aislamiento o cuarentena, debido a las condiciones de vida y a la limitada efectividad de las estrategias de prevención, detección de casos, estudio de contactos y control de la transmisión (Ministerio de Sanidad, 2020).

No es este el lugar para examinar en qué sentido la perspectiva de la vulnerabilidad suple la de la discriminación ${ }^{25}$, sin embargo no está de más señalar que, a la luz de los estudios mencionados en los epígrafes dedicados al grado de infectividad o contagio del virus atendiendo a las distintas categorías sistémicas (clase, género, discapacidad, etc.), más que de mera interrelación entre los tipos de vulnerabilidad, cabría hablar de una dependencia de la vulnerabilidad epidemiológica (y en buena medida, también de la clínica) de la vulnerabilidad social. Esta dependencia se refleja en lo que también se ha llamado vulnerabilidad previa, es decir, la vulnerabilidad en la que ya se encontraban los grupos en los que la pandemia ha impactado de forma más dramática (The Lancet, 2020). Este "eclipse de lo sistémico" aflorará de nuevo en el siguiente epígrafe.

\section{La teoría de los determinantes sociales de la salud y el derecho a la salud}

\subsection{Teorización y definición de la OMS}

Cuando las pandemias se desatan lo que se espera es que sean las personas expertas en salud pública, especialmente profesionales de la medicina, quienes se encarguen de abordarlas (Solanke, 2017: 93). Las miradas y los oídos se dirigen expectantes de información y criterios de actuación a agencias u

\footnotetext{
${ }^{25}$ En sentido contrario, por ejemplo, Morondo (2016) y Barrère (2016).
} 
organismos internacionales como la OMS. Así ha sucedido en casos como los de la gripe aviar, el VIH o el ébola. La autoridad de la OMS, además, ha aumentado progresivamente en la medida en que, sintetizando propuestas previas, ha construido un modelo de salud basado en determinantes sociales, retomado después por la Comisión de los Determinantes Sociales de la Salud, creada al efecto en 2005. Sin embargo, como se verá a continuación, existe una diferencia importante entre la teorización sobre los determinantes sociales de la salud y la definición oficial de la OMS, que repercutirá en su proyección sobre la conceptualización del derecho a la salud.

Desde mediados de los pasados setenta, a la hora de conceptualizar el estado de salud de las personas han ido cobrando peso las teorías que ponen el acento en lo social. Así, Lalonde (1974) se refirió a los determinantes de la salud entendiendo como tales los mecanismos que la determinan o los factores que condicionan la salud de una persona, concretamente, la biología humana, el medio ambiente, los estilos de vida y los sistemas sanitarios. Desde entonces, la horquilla de condiciones que determinan el estado de salud de una persona se ha ido ampliando e incluye diferentes condicionantes relacionados con factores económicos y sociales que, además, visibilizan las inequidades de salud entre distintos grupos sociales. En esta línea, Dahlgren y Whitehead (1991) defienden un nuevo modelo según el cual las inequidades en salud son producto de las interacciones entre distintos niveles de condiciones causales, desde la propia persona hasta las comunidades (Gunning-Schepers, 1999).

Años más tarde, Diderichsen (2001) propone otro modelo según el cual la forma en que son organizadas las sociedades determina la creación de una pirámide de estratificación social y producción de enfermedades según la cual se les asigna a las personas una posición social distinta y es esta posición la que determina sus oportunidades de salud. Este modelo señala que cada sociedad tiene sus mecanismos para generar y distribuir la riqueza y el poder; estos, a su vez, conllevan una exposición diferente a determinadas condiciones que pueden ser perjudiciales para la salud, lo que deriva en una diferente vulnerabilidad en las personas. Tanto la exposición como la vulnerabilidad de la población se va acumulando a lo largo de sus vidas y genera mecanismos de selección. De esta forma, las consecuencias sociales también son diferentes, esto es, la influencia de los eventos de salud en las personas está directamente relacionada con la posición social.

El tercer modelo es el que desarrollan Marmot y Wilkinson (1999). Este modelo, concebido inicialmente con la finalidad de relacionar la perspectiva clínica (curativa) con la de salud pública 
(preventiva), fue aplicado al proceso social que está en la base de las inequidades de salud. El modelo pretende ilustrar cómo estas inequidades condicionadas por los determinantes sociales son la consecuencia de la diferente exposición al riesgo conductual, ambiental y psicológico a lo largo de toda la vida de las personas. También intenta explicar cómo las influencias psicológicas y sociales afectan a la salud física de las personas durante las diferentes etapas de la vida, desde la primera infancia hasta la longevidad ${ }^{26}$.

A partir de estos modelos la OMS lanza uno propio sobre "los determinantes sociales de la salud", que pretende ser integral. En este pueden identificarse dos tipos diferentes de determinantes: los estructurales y los intermedios (Borrell y Artazcoz, 2008). Dentro del primer grupo se encuentran el contexto económico, social y político, así como la posición social que ocupan las personas en la estructura de la sociedad y que, a su vez, es condicionada por la clase, la etnia, el género, los ingresos, la educación, y la ocupación. El segundo grupo hace referencia a las circunstancias materiales que pueden afectar el estado de salud como los factores biológicos, los factores psicosociales, el estilo de vida y el propio sistema sanitario (Padilla y Gullón 2020).

Según el modelo de la OMS, las inequidades socioeconómicas que repercuten en la salud se explican por el efecto de la retroalimentación entre la salud y la posición socioeconómica. En este sentido, puede verse la inequidad, por ejemplo, en el caso de una persona que de pronto debe hacer frente a una disminución en sus ingresos económicos como consecuencia del reconocimiento de un grado de discapacidad en el marco de su actividad laboral, o en el caso de una persona que deba asumir un gasto excesivo para poder acceder al sistema sanitario. Con estos ejemplos es posible apreciar cómo las personas que tienen una salud deteriorada pueden ascender con menor frecuencia en la escala social y descender con más frecuencia que las personas sanas. Esta situación confirma que el sistema sanitario es un determinante social de la salud en sí mismo y que, además, puede interaccionar y modificar el resultado de otros determinantes sociales.

El concepto de posición social es el concepto central en el modelo de la OMS y sirve para comprender cómo funcionan los mecanismos de la inequidad en salud en la creación y reproducción del poder, los

${ }^{26}$ Dentro de este modelo destaca la llamada Hipótesis de Barker (1992), según la cual las desigualdades en salud del presente deben explicarse con base en las condiciones sociales existentes una o incluso dos décadas anteriores, que habrían afectado a la salud de la madre y ésta a su vez al feto, con la consiguiente probabilidad de morbilidad y muerte prematura en la edad adulta. Vid. Barker D.J. (1992) Fetal and infant origins of adult disease. BMJ Publishing Group, London. 
riesgos y la riqueza. Según el estrato social en el que se encuentre una persona, su exposición será desigual a las condiciones y al riesgo de enfermar lo que provoca una vulnerabilidad diferencial. Esta investigación ha tenido un nuevo impulso a partir de las acciones realizadas por la Comisión de los Determinantes Sociales de la Salud. Tras tres años de trabajo, la Comisión (liderada por el profesor Michael Marmot) emitió en 2008 el informe "Subsanar las desigualdades en salud en una generación. Alcanzar la equidad actuando sobre los determinantes sociales en salud", en el que se realiza un llamado a tomar las medidas necesarias para concretar la aspiración de alcanzar la equidad sanitaria en una generación (OMS, 2008) $)^{27}$.

La visión global de la Comisión sobre los Determinantes Sociales de la Salud se sintetiza en la siguiente afirmación:

"la mala salud de los pobres, el gradiente social de salud dentro de los países y las grandes desigualdades sanitarias entre los países están provocadas por una distribución desigual a nivel mundial y nacional, del poder, los ingresos, los bienes y los servicios y por consiguientes injusticias que afectan a la población de forma inmediata y visible (acceso a la atención sanitaria, escolarización, educación, condiciones de trabajo y tiempo libre, vivienda, comunidades, pueblos o ciudades) y a la posibilidad de tener una vida prospera. Esa distribución desigual de experiencias perjudiciales para la salud, no es en ningún caso un fenómeno natural, sino el resultado de una nefasta combinación de políticas y programas sociales deficientes, arreglos económicos injustos y una mala gestión política. Los determinantes estructurales y las condiciones de vida en su conjunto constituyen los determinantes sociales de la salud, que son la causa de la mayor parte de las desigualdades sanitarias entre los países y dentro de cada país" (énfasis añadido).

En resumen, en la teorización de los determinantes sociales de la salud, lo estructural (la posición social) ocupa un lugar central, lo que no ocurre en la definición oficial de la OMS sobre los determinantes sociales de la salud donde, como se verá a continuación, prevalecen las condiciones o circunstancias:

\footnotetext{
${ }^{27}$ En España en el año 2008 se abordó la temática de los determinantes sociales a través de la creación de la Comisión para Reducir las Desigualdades Sociales en Salud en España, formada por un grupo de expertos cuyo trabajo culminó con la publicación del informe "Avanzando hacia la equidad. Propuestas de políticas e intervenciones para reducir las desigualdades sociales en salud en España", si bien sin demasiada trascendencia. Vid. Ministerio de Sanidad, Servicios Sociales e Igualdad. Comisión para reducir las desigualdades sociales en salud en España. Avanzando hacia la equidad. Propuestas de políticas e intervenciones para reducir las desigualdades sociales en salud en $\quad$ España. $\quad$ Madrid 2015.2 Disponible https://www.mscbs.gob.es/profesionales/saludPublica/prevPromocion/promocion/desigualdadSalud/docs/Propuesta_Politicas_Reducir_D esigualdades.pdf (Acceso 7 de junio de 2021).
} 
Los determinantes sociales de la salud son las condiciones en las que la gente nace, crece, vive, trabaja y envejece. Estas circunstancias toman forma en función de la distribución económica, del poder y de los recursos a escala global, nacional y local. Los determinantes sociales de la salud son responsables en su gran mayoría de las inequidades en la salud - las diferenciaciones injustas y evitables en el estado de salud dentro y entre Estados (énfasis añadido) ${ }^{28}$.

Por lo demás, la definición de los determinantes sociales en términos de condiciones o circunstancias deja fuera del concepto de determinante social de la salud un ámbito fundamental del sistema social, como el Derecho. No es extraño, pues, que, en un reciente informe, la Comisión Lancet hable de determinantes legales de la salud (Gostin et al, 2019). A través de una serie de recomendaciones, la Comisión Lancet aconseja que los gobiernos fortalezcan o creen un marco legal, un derecho constitucional o estatutario a la salud o a la protección de la salud, para garantizar la cobertura universal de la salud basada en los derechos, sobre la base de los principios de equidad y no discriminación ${ }^{29}$. Asimismo, advierte de que, incluso cuando el objetivo aparente es la salud pública, hay leyes que pueden institucionalizar la desigualdad, discriminar a las poblaciones ya vulnerables y eliminar las oportunidades para que las poblaciones estigmatizadas accedan a las pruebas y al tratamiento $^{30}$. Se comprende, pues, la necesidad de mencionar la importancia del Derecho como determinante de la salud, pero hablar de determinantes legales de la salud no debe hacer olvidar que el Derecho no es un ámbito independiente de lo social y, por tanto, debería entenderse como un determinante social más de la salud.

\subsection{Proyección sobre el derecho a la salud}

La teoría de los determinantes sociales de la salud ha sido oportuna e interesantemente utilizada para el desarrollo conceptual del derecho a la salud por Lema Añón (2020). Para ello, aún reconociendo que el

${ }^{28}$ Traducción propia. Texto original: The social determinants of health are the conditions in which people are born, grow, live, work and age. These circumstances are shaped by the distribution of money, power and resources at global, national and local levels. The social determinants of health are mostly responsible for health inequities - the unfair and avoidable differences in health status seen within and between countries.

${ }^{29}$ Así, a lo largo de la historia, las leyes equivocadas, desactualizadas, arbitrarias o discriminatorias habrían causado un gran daño.

${ }^{30}$ Algunas leyes españolas son un buen ejemplo de ello dado que siguen sin permitir el acceso de las personas con VIH, entre otras condiciones de salud, al ejercicio de determinados empleos públicos. Cabe señalar que en los últimos años ha habido avances normativos para acabar con la exclusión de las personas con VIH en las convocatorias de empleo público para el acceso a los cuerpos y fuerzas de seguridad del Estado. Vid. Ramiro Avilés, M. Á., Ramírez Carvajal, P. (2018). La exclusión de las personas con VIH de los cuerpos uniformados de seguridad en España. Revista Vasca de Administración Pública (112), 209-243. 
artículo 12 del Pacto Internacional de Derechos Económicos, Sociales y Culturales (PIDESC) de 1966 no toma en consideración la idea de los determinantes sociales de la salud "más que de forma indirecta y, en todo caso muy matizada" (Lema Añón, 2020: 297), el autor sostiene que hay al menos dos razones para abrir la interpretación de ese derecho a dicha consideración (Lema Añón, 2020: 297-301).

En primer lugar, el vínculo de dicha idea con el artículo 25 de la Declaración Universal de los Derechos Humanos, profundizado después, no tanto por el artículo 12 del PIDESC ya mencionado, sino por la interpretación del mismo plasmada en la Observación General número 14 (2000) del Comité de Derechos Económicos, Sociales y Culturales del Consejo Económico y Social de las Naciones Unidas. En este documento -apunta Lema- "se reconoce el estrecho vínculo entre el derecho al más alto nivel posible de salud física y mental y otros derechos humanos cuyo contenido aparece en muchos casos conectado con determinantes sociales de la salud (derechos a la alimentación, a la vivienda, al trabajo, a la educación, a la dignidad humana, a la vida, a la no discriminación, a la igualdad, a no ser sometido a torturas, a la vida privada, al acceso a la información, a la libertad de asociación, reunión y circulación, etc.” (Lema Añón, 2020: 298).

La segunda razón, y de mayor relevancia, tendría que ver con la investigación sobre los determinantes sociales de la salud. De esta investigación se destacan dos elementos diferenciados, en virtud de que "afectan tanto al nivel de salud de una población como a las desigualdades de salud en el seno de esa población” (Lema Añón, 2020: 299). En función de esta distinción se plantean "dos fines valiosos pero diferentes, como son aumentar el nivel de salud y reducir las desigualdades (injustas) de salud" que "podrían plantearse como aproximaciones complementarias o como alternativas, pero en todo caso aluden a estrategias diferentes de las tradicionales basadas en el acceso a la asistencia sanitaria" (ibídem). Lema insiste en que, aunque ambos formen parte del contenido del derecho a la salud, se trata de dos objetivos diferentes (ibídem) que, consecuentemente, han de ser incorporados de manera diferente (Lema Añón, 2020: 300). Entre ambas dimensiones, nivel de salud y desigualdades de salud, no habría jerarquía, y mientras la primera integraría la dimensión técnica del derecho a la salud, la segunda se vincularía con la discusión de la justicia social (Lema Añón, 2020: 300-1).

No cabe duda de que una teorización del derecho a la salud en los términos transcritos incorpora una dimensión socio-sistémica que va más allá de lo que ha dado la interpretación del derecho a la salud como simple acceso a la asistencia sanitaria sin discriminación. Por ese lado, pues, merece ser 
celebrada. Mayor escepticismo plantearía la aceptación de la independencia y falta de jerarquía de los elementos del derecho a la salud (entre el nivel de salud y las desigualdades de salud) si fuera este el planteamiento de Lema. Para ello valgan de nuevo los estudios citados en este trabajo. En ellos ha quedado clara la enorme dependencia que, ante el SC-2, presenta el nivel de salud de las personas de las desigualdades (producidas por los determinantes) de la salud en el contexto de la pandemia. Como hemos visto en el capítulo 2, vivir en condiciones de hacinamiento o insalubridad, trabajar de jornaleros/as, sin poder guardar distancias o sin la debida protección ha pasado factura al nivel de salud de cierto sector de la población que, de otra manera, no se hubiera visto contagiado y enfermado en la desproporción en la que lo ha hecho.

\section{La tutela antidiscriminatoria en el derecho a la salud}

\subsection{La igualdad sustantiva como corrección al falso universalismo}

Afirmar que vivimos en una sociedad en la que anida la desigualdad parece una verdad incontestable. Sin embargo, el debate social sobre esta realidad es amplio, y es muy posible (y comprensible) que quien piense que vivimos en una sociedad justa no tenga la misma visión de la desigualdad, ni de la igualdad, que quien opine que vivimos en una sociedad injusta. Pero incluso entre quienes consideran que nuestras sociedades son injustas tampoco suele haber acuerdo sobre cómo y por qué se produce tal desigualdad. Las teorías explicativas se combinan con las valorativas, y entre este ser y deber ser se inspiran y elaboran políticas y leyes.

Un principio explicativo del Derecho moderno que admite poca discusión es el del falso universalismo. El Derecho se proclama universalista en derechos, pero la proclama es una ficción, tanto en su origen (dada la exclusión de: mujeres, personas afrodescendientes, no propietarias, etc.) como en su evolución (dada la construcción o configuración de los derechos en función de un modelo de sujeto varón, blanco, propietario, sin discapacidades, etc.). De hecho, para corregir este falso universalismo se han formulado teorías y modelos de igualdad. Entre los más recientes se encuentra el modelo de igualdad inclusiva previsto en la Observación General 6 aprobada por el Comité sobre los Derechos de las Personas con Discapacidad (en adelante OG6) ${ }^{31}$ en 2018. En este documento se hace hincapié en la transición desde un modelo de igualdad formal hacia un modelo de igualdad sustantiva. La igualdad formal -se afirma-

${ }^{31} \mathrm{CRPD} / \mathrm{C} / \mathrm{GC} / 6$, Aprobada por el Comité en su $19^{\circ}$ período de sesiones (14 de febrero a 9 de marzo de 2018). 
lucha contra la discriminación directa tratando de manera similar a las personas que están en situación similar, y puede ayudar a combatir los estereotipos negativos y los prejuicios, pero no puede ofrecer soluciones al dilema de la diferencia. La igualdad sustantiva, en cambio, aborda también la discriminación indirecta y estructural, y tiene en cuenta las relaciones de poder. La OG6 propone, entonces, un nuevo modelo de igualdad que abarca un modelo de igualdad sustantiva, pero que al mismo tiempo amplía y detalla el contenido de la igualdad a través de una serie de dimensiones ${ }^{32}$.

En el modelo planteado en la OG6 tiene una indudable influencia el trabajo de Fredman (2016), quien establece un enfoque cuatridimensional de la igualdad sustantiva. Las cuatro dimensiones que exige el modelo de igualdad inclusiva requieren profundizar en ciertos principios clave en materia de derechos humanos. En primer lugar, el derecho a la igualdad inclusiva debe tratar de corregir las desventajas desde políticas redistributivas. En segundo lugar, debe contrarrestar los prejuicios, el estigma, los estereotipos, la humillación y la violencia basados en una condición, a través de políticas de reconocimiento $^{33}$. En tercer lugar, debe ampliar la voz y la participación, contrarrestando la exclusión política y social, e incluyendo, asimismo, la perspectiva interseccional. Finalmente, debe ajustar la diferencia y proponer un cambio estructural, para lo cual resulta ineludible la garantía del diseño de una sociedad pensada para un universo real de personas y situaciones, que conlleva garantizar, entre otras herramientas, el "derecho a la accesibilidad universal", medidas de apoyo y ajustes razonables (Palacios, 2020).

En definitiva, la igualdad sustantiva de la OG6 incluye la necesaria reacción contra prejuicios, estigma, estereotipos, humillación y violencia, propone un cambio estructural con perspectiva interseccional y, además, protagonizado por quienes son víctimas de discriminación. Sin embargo, como se detallará a continuación, la tutela antidiscriminatoria prevista en el Derecho no se basa en la igualdad sustantiva sino en la igualdad de trato y -a lo sumo- en la igualdad de oportunidades.

\section{2. El concepto jurídico de discriminación}

La referencia a la discriminación viene históricamente incluida en las fórmulas antidiscriminatorias de textos internacionales que, a su vez, son incorporadas a las constituciones estatales. Por ejemplo, en el

\footnotetext{
32 Idem

${ }^{33}$ En el sentido que le brinda el art. 3 inc. d) de la Convención Internacional sobre los Derechos de las Personas con Discapacidad
} 
caso español se encuentra recogida en el artículo 14 del texto constitucional (CE): "Los españoles son iguales ante la ley, sin que pueda prevalecer discriminación alguna por razón de nacimiento, raza, sexo, religión, opinión o cualquier otra condición o circunstancia personal o social”.

La prohibición de la discriminación a continuación de la referencia a la igualdad ante la ley, y sin mención alguna a la igualdad de los grupos (también llamada efectiva) -que, siguiendo con el caso español, se contempla en el artículo 9.2 CE- ha condicionado el concepto de discriminación de la cultura jurídica y, por tanto, el desarrollo del derecho antidiscriminatorio. Otro factor determinante en el mismo sentido es el de la tipificación de la discriminación. A este respecto resulta conocido el binomio según el cual la discriminación puede ser directa o indirecta (Barrère, 2019: 285 y ss.; Añón Roig, 2013). En Europa, la normativa de la Unión Europea ha jugado un papel primordial, tanto sobre la formulación del binomio como en su desarrollo jurisprudencial. Son bastantes las Directivas que se pueden citar al respecto (Directiva 76/207/CEE, Directiva 97/80/CE, Directiva 2000/43/CE, Directiva 2000/78/CE, Directiva 2002/73/CE, Directiva 2004/113/CE, Directiva 2006/54/CE). En este despliegue normativo, la conceptualización de la discriminación ha sido uniforme en lo que respecta a su tipificación. Ha sufrido variaciones, en cambio, el elemento identificador de la discriminación. Para ilustrar esta cuestión se comparará la tipificación de la discriminación directa e indirecta de las directivas del 2000 con la de las posteriores de 2002 y 2006.

Según el artículo 2 de las Directivas del 2000, existirá discriminación directa cuando una persona sea tratada (por los motivos referidos en la Directiva) de manera menos favorable que otra en situación comparable o análoga; existirá discriminación indirecta cuando una disposición, criterio o práctica aparentemente neutros sitúe a personas de ciertas características reflejadas en las directivas en desventaja particular respecto de otras. En definitiva, el peso caracterizador de la discriminación recae, por decirlo de alguna manera, en el trato o conducta agente. Sin embargo, tanto en la Directiva de 2002, como luego en la de 2006 (referidas a la igualdad de mujeres y hombres), el peso caracterizador se desplaza a la situación: se entenderá por discriminación directa "la situación en que una persona sea, haya sido o pudiera ser tratada de manera menos favorable que otra en situación comparable por razón de sexo" (cursiva añadida); mientras que se entenderá por discriminación indirecta "la situación en que una disposición, criterio o práctica aparentemente neutros sitúan a personas de un sexo determinado en desventaja particular con respecto a personas del otro sexo, salvo..." (cursiva añadida). Obsérvese 
bien: el desplazamiento tiene lugar incluso aunque, en el caso de la discriminación indirecta, se tenga que hablar tautológicamente, de "una situación que sitúa".

Independientemente de las razones, incluso loables, que hayan podido influir para tal desplazamiento ${ }^{34}$, este no solo desdibuja el origen conceptual de la discriminación (el trato, sin el que no hay situación), sino que lo hace reductivamente, pues una cosa es el trato y otra las consecuencias de ese trato (es decir, las situaciones que ese trato puede producir). Además, abandonar la figura del trato en la tipificación de la discriminación conlleva renunciar gratuitamente a un enorme potencial clasificador inexplorado en el Derecho antidiscriminatorio. Piénsese, en este sentido, que si se considera que un trato no es más que una conducta hacia alguien o algo (Westen, 1990: 94), este podrá ser clasificado de múltiples maneras (como consciente o inconsciente, activo o pasivo, individual o colectivo, lingüístico o extralíngüístico, etc.).

Entre las diversas clasificaciones posibles adquiere especial relevancia la que distingue a los tratos en activos y pasivos (o, en otros términos, de acción y de omisión), hoy por hoy ausente en el Derecho antidiscriminatorio $^{35}$, cuando la discriminación por omisión o por inacción ${ }^{36}$ puede adquirir un enorme potencial inspirado en el modelo de igualdad sustantiva mencionado anteriormente. Es más, teniendo en cuenta el deber constitucional que tienen los poderes públicos de tomar medidas para promover esa igualdad (en el caso español, el artículo 9.2 CE) cabría deducir que, en tanto no las toman, discriminan por omisión.

\subsection{La introducción de la discriminación estructural, sistémica, o subordiscriminación.}

Los tribunales han ido desarrollando la tipificación de la discriminación en al menos dos sentidos: uno formal y otro sustantivo. Como ejemplo del primero, tanto el Tribunal de Justicia de la Unión Europea (Sentencia de 17 de julio de 2008, as. C-303/06, Coleman) como el Tribunal Europeo de Derechos

\footnotetext{
34 En hipótesis, desvincular la discriminación de la intencionalidad que se suele atribuir a las conductas y, por tanto, no requerir que la conducta sea intencional para que se pueda hablar de discriminación.

${ }^{35}$ El caso español es un claro ejemplo de la falta de adecuación de la protección antidiscriminatoria a estos escenarios. En este sentido, es importante destacar que actualmente existe una propuesta legislativa que pretende reconocer nuevos contextos y situaciones que producen comportamientos discriminativos. Ver: Proposición de ley integral para la igualdad de trato y la no discriminación (2021), del Grupo Parlamentario Socialista de las Cortes Generales.

${ }^{36}$ Conviene precisar que lo que aquí se denomina discriminación por omisión (por inacción) no coincide con la llamada "discriminación por indiferenciación o igualación” (Rey Martínez 2001, 171), a la que también se suele denominar "discriminación por omisión”. Y es que la discriminación por inacción puede referirse tanto a un trato diferenciador como indiferenciador.
} 
Humanos (Sentencia de 22 de marzo de 2016, as. Guberina contra Croacia) han extendido el concepto de discriminación directa para designar el supuesto en que una persona que entabla una demanda por discriminación con base en una característica protegida que no posee sea amparada por su vinculación o asociación con otra persona que sí la posee ${ }^{37}$. Desde la perspectiva de la igualdad sustantiva, la Corte Interamericana de Derechos Humanos se ha hecho eco tanto de la terminología como del concepto de discriminación estructural en diversas sentencias (Troncoso y Morales, 2017), entre las cuales merecen ser citadas las relativas a los casos González y otras (Campo Algodonero) con México, 16 de noviembre de 2009; Atala Riffo y niñas con Chile, 24 de febrero de 2012; y Trabajadoras de la Hacienda Brasil Verde con Brasil, 20 de octubre de 2016. Por lo demás, aunque no se utilice la adjetivación estructural en relación a la discriminación, la jurisprudencia constitucional española también utiliza ese adjetivo para designar la desigualdad histórica de las mujeres que contrastaría con la igualdad sustantiva definidora de la ciudadanía ${ }^{38}$.

De esta manera, aunque el derecho legislado no recoge la definición de la discriminación estructural, el concepto -acuñado originariamente por el pensamiento crítico como "racismo institucionalizado"39 y teorizado por la doctrina durante más de cinco décadas con denominaciones como "discriminación institucional", “discriminación sistémica" o "subordiscriminación” (Barrère, 2019)-, aun dentro de su complejidad, se abre paso jurisprudencialmente y a través de organismos que velan por los derechos humanos. Por ejemplo, la Comisión de los Derechos de la Personas y de la Juventud de Quebec señala que "la discriminación sistémica implica tanto la discriminación directa como la indirecta, pero además va mucho más allá. Es decir, está basada en la interacción dinámica entre las decisiones y las actitudes viciadas por el prejuicio, y en modelos organizativos y prácticas institucionales que tienen efectos perjudiciales, tanto si son queridos como si no" (Commission Québec, 2011: 14), apuntando en este

\footnotetext{
37 Vid, una reciente utilización de esta tipificación en la STC 71/2020, de 29 de junio, donde se utiliza para designarla la expresión “discriminación refleja” (FJ 3).

${ }^{38}$ Vid. así la STC 91/2019, de 3 de julio (FJ 10).

${ }^{39}$ La primera referencia al término "racismo institucionalizado" aparece en 1968 acuñada por Carmichael y Hamilton para referirse a un racismo que formaba parte de la sociedad norteamericana en su conjunto, de sus instituciones y también practicado individualmente, y que se mostraba en determinadas conductas al tiempo que permanecía oculto. Se trataría de un racismo que actúa a través de las instituciones, con independencia de las actitudes de los individuos que forman parte de las mismas. Se considera como un racismo acrítico más que inconsciente (Bowling y Phillips, 2002: 40), en el sentido de que quienes lo llevan a la práctica no tienen en cuenta las consecuencias de sus actuaciones para las minorías étnicas que lo sufren (Bowling, 1998: 3-4). Un ejemplo de prácticas de racismo institucionalizado en nuestro país se expone en García Añón, J., et al 2013.
} 
último sentido a prácticas que se consideran naturales (naturalizadas), o que entran dentro de la normalidad (García Añón et al, 2013: 73) 40. $^{40}$

En definitiva, las prácticas sistemáticas del racismo (sexismo ${ }^{41}$, clasismo, capacitismo, edadismo, etc.) institucionalizado son algo que va más allá de la tipificación clásica de la discriminación en el ámbito jurídico (ruptura puntual e individualizada de la igualdad de trato, que da lugar a la discriminación directa y la indirecta). Implica abrir el concepto de discriminación a un trato que no es episódico ni circunstancial sino, además de sistemático (Añón Roig, 2013), "sistémico", es decir, que encuentra significación en un conjunto no cerrado de elementos heterogéneos (prejuicios, creencias, normas, mitos, estereotipos, roles, tratos, etc.) que producen jerarquizaciones intergrupales de poder ${ }^{42}$.

Identificado el concepto, ahora se trata de ilustrar su funcionalidad en un escenario como el descrito en los informes sobre la irrupción de la pandemia que se han tomado en consideración en el apartado segundo de este trabajo. Entre las situaciones detectadas se escogerá como ejemplo el de la expansión desproporcionada del SC-2 en viviendas hacinadas en las que las personas no pueden distanciarse ${ }^{43}$, aun queriéndolo, de otras contagiadas. Tal como está tipificada la discriminación en nuestros ordenamientos, difícilmente este caso podría calificarse como tal, bien porque falta el tertium comparationis (discriminación directa) o porque no hay una norma, disposición o criterio neutro identificables que sean los que repercutan negativa y desproporcionadamente sobre dichas personas. Sin embargo, las personas no viven hacinadas por decisión propia, y menos ante el riesgo de contagio; viven de ese modo por su clase y porque un (complejo, sí, pero identificable) trato institucional no les ha facilitado alternativas. En otros términos, sufren un mayor y desproporcionado número de contagios porque el sistema clase (interseccionado con otros) les discrimina estructuralmente, y porque ese otro sistema, el jurídico-político, en tanto no responda a esa discriminación, contribuye a su reproducción (id. est, discrimina por omisión).

\footnotetext{
${ }^{40}$ Según el Tribunal Supremo de Canadá "La discriminación (sistémica) se refuerza por la alta exclusión del grupo desaventajado, porque esta exclusión fomenta la creencia, tanto dentro como fuera del grupo, de que la exclusión es resultado de fuerzas "naturales". Action Travail des Femmes v. Canadian National, [1987] 1 R.c.S. 1114, 1139 (1987) 8 c.H.R.R. D/4210 (S.c.c.). citado en Commission Québec, 2011: 14

${ }^{41}$ Una investigación previa en este sentido puede ser consultada en Añón Roig, 2020.

42 Para un mayor desarrollo del concepto de sistema adoptado aquí, vid. Barrère 2019, p. 327 y ss.

${ }^{43}$ En este sentido ver el apartado 2.a de la presente investigación. Asimismo: Cuerdo-Vilches T., et al, 2020.
} 


\section{Consideraciones conclusivas}

La irrupción de la pandemia ocasionada por el SC-2 ha amplificado la desigualdad estructural y la insuficiencia del modelo de Derecho antidiscriminatorio clásico o liberal. La llamada igualdad formal (igualdad ante la ley o igualdad de trato) o el concepto de discriminación que subyace al binomio discriminación directa/discriminación indirecta, que es como se suelen interpretar las fórmulas antidiscriminatorias, no garantizan el acceso al derecho a la salud sin discriminación.

La teoría de los determinantes sociales de la salud supone un gran avance en la delimitación del derecho a la salud en igualdad, pero definiendo a los determinantes como condiciones o circunstancias (es decir, como algo personal o esporádico, respectivamente) la OMS no termina de ofrecer una fórmula o esquema interpretativo de la igualdad y no discriminación que permita integrar en la cultura jurídica lo que aquí se ha denominado discriminación estructural, sistémica o subordiscriminación.

La conceptualización del derecho a la salud, como la de cualquier derecho (incluyendo el de igualdad y no discriminación) ni es algo inocente ni neutral. Tampoco lo es la implementación de los derechos a nivel político o su aplicación a nivel judicial. Un derecho a la salud en tiempos de pandemia exige activar el deber de los poderes públicos a promover la igualdad sustantiva ya que, en caso de no hacerlo, estarán discriminando por omisión (su inacción estará haciendo que ciertas personas vean afectados tanto su derecho a la salud como su estado de salud negativa y desproporcionadamente). Partiendo de un esquema de la discriminación como fenómeno sistémico de jerarquización intergrupal no es posible hacer justicia igualitaria con medidas hacia la "población general" (Sontag, 2016: 193). Si el SC-2 se expande desproporcionadamente, el derecho a la salud sin discriminación exigirá actuar sobre lo que produce esa desproporción, que no es el virus sino la desigualdad estructural previa.

Desde un modelo de igualdad sustantiva en el derecho a la salud, las medidas más urgentes ante la pandemia deberían de ir encaminadas a quienes mayor riesgo de contagio y enfermedad tienen. Demostrada la dependencia de ese riesgo de la posición derivada de los sistemas de poder, las medidas tendrían que seguir un principio de actuación que incluyera las cuatro dimensiones de la igualdad sustantiva ya mencionadas. En primer lugar, el desarrollo de políticas que fortalezcan una dimensión redistributiva justa para afrontar las desventajas socioeconómicas. A la luz de los estudios y la información recopilada en el segundo apartado de este trabajo esto podría hacerse actuando sobre los 
hogares con mayor riesgo de contagio, debido a la superficie de la vivienda y al número de personas convivientes en ella; equipando de servicios de todo tipo (sanitarios, habitacionales, distribución de alimentos, etc.) a los barrios con menor nivel socioeconómico; y teniendo presente que la situación de precariedad económica en la que viven gran parte de las personas con discapacidad exige su reflejo en las políticas fiscales.

En segundo término, se hace necesario profundizar en una política de reconocimiento y de este modo combatir el racismo, el sexismo, el clasismo, el capacitismo, el edadismo, etc., así como el estigma, los estereotipos, los prejuicios y la violencia aparejados. A dichos fines, parece imperioso proteger al sector de los cuidados, tanto en relación al personal que trabaja en centros sanitarios como al que trabaja en el ámbito doméstico; inspeccionar las condiciones laborales y habitacionales del personal temporero en explotaciones hortofrutícolas y denunciar o, en su caso, reparar la propagación de noticias con tintes racistas y xenófobos; establecer protocolos de actuación a la hora de decidir cómo se utilizan los recursos sanitarios en situaciones de escasez (por ejemplo, las UCI) sin discriminación por edad (o, lo que es igual, sin seleccionar la edad como el criterio relevante para poder beneficiarse del recurso) o por discapacidad (como ha sido el caso citado denunciado por el CERMI).

En tercer lugar, la igualdad sustantiva exige el desarrollo y potenciación de una dimensión participativa de las personas y de grupos especialmente excluidos. En este sentido parece necesario atender y priorizar a la población institucionalizada (residencias de personas mayores y/o de personas con discapacidad; centros penitenciarios, etc.) y habilitar espacios para la participación de colectivos que tienen mucho que decir desde su experiencia de encierro forzoso, que es consecuencia de barreras que impiden la participación social y política. Y desde dichos espacios garantizar que la evaluación del impacto de la igualdad sea un elemento esencial de su monitoreo y revisión de las respuestas frente a la pandemia, y de sus efectos sobre el terreno. En este proceso la recopilación de datos sobre las experiencias y los resultados de los grupos expuestos a la discriminación estructural parece un instrumento fundamental.

Finalmente, una igualdad sustantiva e inclusiva exige ajustes para dar cabida a la diversidad como un aspecto de la condición humana. Ello obliga al diseño de una política pública inclusiva, en clave universal e interseccional (de género, de discapacidad, de edad, etc.) que garantice condiciones de accesibilidad, medidas de apoyo y adopción de ajustes razonables en el acceso a los sistemas de salud. 


\section{BIBLIOGRAFÍA}

ALMIRÓN MENGÍBAR, A. (2020), "La pandemia del coronavirus, una crisis del sistema con los cuidados en el centro", Mientras tanto, $\mathrm{n}^{\circ} 190$.

AÑÓN ROIG, M. J. (2013), “Principio antidiscriminatorio y determinación de la desventaja”, Isonomía, 39: 127-157.

AÑÓN ROIG, M. J. (2020), “Transformations in anti-discrimination law: progress against subordination”, Revus, 40: 1-17.

BARKER D.J. (1992), Fetal and infant origins of adult disease. Londres: BMJ Publishing Group.

AZAROLA A, CORTÁZAR A DE, PERNETT J, PIÑAN O. (2020), Repercusiones del coronavirus en poblaciones en situación de vulnerabilidad social: personas migrantes y minorías étnicas. Escuela Andaluza de Salud Pública [Internet]. Disponible en: https://www.easp.es/web/coronavirusysaludpublica/repercusiones-del-coronavirus-enpoblaciones-en-situacion-de-vulnerabilidad-social-personas-migrantes-y-minorias-etnicas/

BARRÈRE UNZUETA, M. (2016), "Derecho antidiscriminatorio, interseccionalidad y categorías sistémicas: análisis y propuestas con proyección legislativa". La Barbera, M. C., y Cruells López, M. (coords) Igualdad de género y no discriminación en España: evolución, problemas y perspectivas, Centro de Estudios Políticos y Constitucionales, Madrid, 455-479.

BARRÈRE UNZUETA, M. (2016), “Martha A. Fineman y la igualdad jurídica: ¿Vulnerabilidad vs. Subordiscriminación?”, Cuadernos Electrónicos de Filosofía del Derecho, 34:17-34.

BARRÈRE UNZUETA, M. (2019), Feminismo y Derecho. Fragmentos para un Derecho antisubordiscriminatorio. Santiago de Chile: Olejnik.

BAENA-DÍEZ, JM., BARROSO, M., CORDEIRO-COELHO, SI., DÍAZ JL., GRAU, M. (2020), "Impact of COVID-19 outbreak by income: hitting hardest the most deprived", Journal of Public Health, fdaal 36, https://doi.org/10.1093/pubmed/fdaa136

BEAUNOYER E, DUPÉRÉ S, GUITTON MJ (2020), “COVID-19 and digital inequalities: Reciprocal impacts and mitigation strategies". Comput Human Behav. 1; 111.

BODENMANN P, PAHUD-VERMEULEN B, BOUCHE L, ZOZAYA JS, BAUERMEISTER M, BERZIG A (2020), "Left behind populations, COVID-19 and risks of health inequities: a guide of the local social-health network (Vaud, Switzerland)". Rev Med Suisse.16 (Nº 691-2):859-62.

BORRELL C, ARTAZCOZ L (2008), "Políticas para disminuir las desigualdades en salud". Gaceta Sanitaria. 22(5):46573.

BOSCH N, et al. (2020), IEB Report 4/2020. Barcelona: Institut d'Economia de Barcelona y Universitat de Barcelona.

CHEN JT, y KRIEGER N. (2021), "Revealing the Unequal Burden of COVID-19 by Income, Race/Ethnicity, and Household Crowding: US County Versus Zip Code Analyses”. J Public Health Manag Pract. Jan/Feb; 27 Suppl 1.

DAHLGREN G, WHITEHEAD M. (1991), Policies and Strategies to Promote Social Equity in Health. Estocolmo, Suecia: Institute for Futures Studies.

DEFENSOR DEL PUEBLO (2019), Recomendaciones para garantizar el derecho a la salud [Internet]. Disponible en: https://www.defensordelpueblo.es/noticias/asistencia-sanitaria-universal/

DEL RÍO-LOZANO M, GARCÍA-CALVENTE MM, MARTÍN-BARATO A. (2020), "Los cuidados y la salud de las mujeres. Instituto Andaluz de la Mujer". Cuadernos para la Salud de las Mujeres. № 3. 
DIDERICHSEN, EVANS y WHITEHEAD. (2001), “The social basis of disparities in health", en Evans et al. (eds). Challenging inequities in health: from ethics to action. Nueva York: Oxford UP.

EAPN (2020), Nuevas necesidades observadas por las entidades sociales ante el coronavirus [Internet]. Disponible en: https://www.eapn.es/covid19/publicaciones/10/nuevas-necesidades-observadas-por- las-entidades-sociales-ante-elcoronavirus

FUNDACIÓN FOESSA (2020), Distancia social y derecho al cuidado. https://caritas-web.s3.amazonaws.com/mainfiles/uploads/2020/06/CÁRITAS-analisis-y-persectivas-digital-00000002.pdf

GONZÁLEZ-RÁBAGO Y, CABEZAS-RODRÍGUEZ A, MARTÍN U. (2021), Social Inequalities in Health Determinants in Spanish Children during the COVID-19 Lockdown. International Journal of Environmental Research and Public Health, 18(8):4087.

GOSTIN L. O., ET AL (2019), "The legal determinants of health: harnessing the power of law for global health and sustainable development”. Lancet. 4; 393 (10183):1857-1910. doi:10.1016/S0140-6736(19)30233-8.

GUNNING-SCHEPERS L. J. (1999), “Models: instruments for evidence-based policy”. Epidemiology Community Health; 53:263.

IDA (2020), Hacia una respuesta inclusiva de la discapacidad frente a la Covid-19: 10 recomendaciones de la Alianza Internacional de Discapacidad, 19 de marzo.

KLUGE HHP, JAKAB Z, BARTOVIC J, D'ANNA V, SEVERONI S. (2020), "Refugee and migrant health in the COVID19 response”. Lancet 395(10232):1237-9

LALONDE M A. (1974), New Perspective on the Health of Canadians, Otawa, Office of the Canadian Minister of National Health and Welfare.

LAZARUS JV, RATZAN S, PALAYEW A, BILLARI FC, BINAGWAHO A, ET AL. (2020), "COVID-SCORE: A global survey to assess public perceptions of government responses to COVID-19 (COVID-SCORE-10)". PLOS ONE 15(10): e0240011. https://doi.org/10.1371/journal.pone.0240011

LEMA AÑÓN, C. (2020), "La revolución de los determinantes sociales de la salud: derecho a la salud y desigualdad", Anuario de Filosofia del Derecho, tomo XXXVI, pp. 289-317.

MADRID PÉREZ, A. (2020), "Las desigualdades de la pandemia”, Mientras tanto, nº 191.

MARMOT M, WILKINSON R, (eds.) (1999), Social Determinants of Health. Oxford University Press.

MÉDICOS DEL MUNDO (2020), ¿Qué pasa con quienes no tienen casa ni acceso a la sanidad? [Internet]. Disponible en: https://www.medicosdelmundo.org/actualidad-y-publicaciones/noticias/que-pasa- con-quienes-no-tienen-casa-niacceso-la-sanidad

MINISTERIO DE SANIDAD (2020), Equidad en Salud y COVID- 19. Análisis y propuestas para abordar la vulnerabilidad epidemiológica vinculada a las desigualdades sociales. Madrid. Disponible en: https://www.mscbs.gob.es/profesionales/saludPublica/ccayes/alertasActual/nCov/documentos/COVID19 Equidad en salud y COVID-19.pdf

MORONDO TARAMUNDI, D. (2016), ¿Un nuevo paradigma para la igualdad? La vulnerabilidad entre condición humana y situación de indefensión”, Cuadernos Electrónicos de Filosofía del Derecho, 34: 205-221.

OMS (2008), Subsanar las desigualdades sanitarias en una generación. Alcanzar la equidad sanitaria actuando sobre los determinantes sociales de la salud. $1^{\text {a }}$ Edición ed. Ginebra: Organización Mundial de la Salud. Disponible en: https://apps.who.int/iris/bitstream/handle/10665/69830/WHO_IER_CSDH_08.1_spa.pdf?sequence=1\&isAllowed=y

ONU (2020), Informe de políticas: una respuesta a la Covid-19 inclusiva de la discapacidad, 20-06753. 
ONUSIDA (2020), Las trabajadoras sexuales no deben quedarse atrás en la respuesta ante la COVID-19. Nota de prensa $\begin{array}{lllll}\text { del } & 8 & \text { de } & \text { abril } & \end{array}$ https://www.unaids.org/es/resources/presscentre/pressreleaseandstatementarchive/2020/april/20200408_sex-workerscovid-19

OXFAM (2020), El coronavirus no discrimina, las desigualdades sí. Disponible en: https://medium.com/@,Oxfam/elcoronavirus-no-discrimina-las-desigualdades-s\%C3\%AD-8e 54241388e 0

PADILLA, J, GULLÓN, P. (2020), Epidemiocracia. Nadie está a salvo sino estamos todos a salvo. Madrid: Capitán Swing.

PALACIOS, A. (2020), "Discapacidad y derecho a la igualdad en tiempos de pandemia", Revista Pensar, Fortaleza, 25-4: $1-14$.

PLATAFORMA DE ORGANIZACIONES DE PACIENTES (2020), Estudio del impacto de COVID-19 en las personas con enfermedad crónica $\quad$ [Internet]. Disponible https://www.plataformadepacientes.org/sites/default/files/informe_covid19_final_web_ok.pdf

RAMIRO AVILÉS, M. A. Y RAMÍREZ CARVAJAL, P. (2018), La exclusión de las personas con VIH de los cuerpos uniformados de seguridad en España. Revista Vasca de Administración Pública (112), 209-243.

RENDUELES, C. (2020), Contra la igualdad de oportunidades. Un panfleto igualitarista. Seix Barral: Madrid.

REY MARTÍNEZ, F. (2011), “De qué hablamos cuando hablamos de igualdad constitucional?”, Anales de la Cátedra Francisco Suárez, 45: 167-181.

RIGHTS INTERNATIONAL SPAIN (2020), Afrodescendientes. Crisis sanitaria COVID-19: racismo y xenofobia durante el estado de alarma [Internet]. Disponible http://www.rightsinternationalspain.org/uploads/publicacion/d0b782ac0452e9052241b17a646df19a d4edf12c.pdf

RUIZ CANTERO, M. T. (2020), "Las estadísticas sanitarias y la invisibilidad por sexo y de género durante la epidemia de COVID-19”, Gaceta Sanitaria, 4 mayo https://www.gacetasanitaria.org/es-las-estadisticas-sanitarias-invisibilidad-poravance-S0213911120300911

RUIZ-PÉREZ, I. Y PASTOR-MORENO, G. (2020), "Medidas de contención de la violencia de género durante la pandemia de COVID-19”, Gaceta Sanitaria, https://doi.org/10.1016/j.gaceta.2020.04.005.

SOLANKE, I. (2017), Discrimination as Stigma. A Theory of Anti-discrimination Law. Portland: Hart.

SONTAG, S. (2016), La enfermedad y sus metáforas. El sida y sus metáforas. Barcelona: Penguin.

The Lancet (2020), Redefining vulnerability in the era of COVID-19, The Lancet, Volume 395, Issue 10230, Page 1089, https://doi.org/10.1016/S0140-6736(20)30757-1.

(https://www.sciencedirect.com/science/article/pii/S0140673620307571)

TRABAJANDO EN POSITIVO (2020), Informe sobre el impacto de la Covid-19 en colectivos en exclusión social y sus necesidades prioritarias [Internet]. Disponible http://www.trabajandoenpositivo.org/documentos/informe necesidadesycolectivos covid19.pdf

TRONCOSO ZÚÑIGA, C. Y MORALES CERDA, N. P. (2017), “Caso Duque con Colombia: Un caso de discriminación estructural”, Anuario de Derechos Humanos, 13:135-145. Doi: 10.5354/0718-2279.2017.46895.

TURNER-MUSA, J., AJAYI, O., y KEMP, L. (2020), “Examining Social Determinants of Health, Stigma, and COVID-19 Disparities". Healthcare (Basel, Switzerland), 8(2), 168. https://doi.org/10.3390/healthcare8020168

VALERO ALZAGA E, MARTÍN RONCERO U, DOMÍNGUEZ-RODRÍGUEZ A, GRUPO CONFISALUD. (2020), Covid-19 y salud infantil: el confinamiento y su impacto según profesionales de la infancia. Rev Esp Salud Pública, 94: 27 de julio e202007064 
VIEIRA, C.M., FRANCO, O.H., RESTREPO, C.G., ABEL, T. (2020), "COVID-19: The forgotten priorities of the pandemic". Maturitas, 136: 38-41.

WANG Z, y TANG K (2020), Combating COVID-19: health equity matters. Nat Med. 1;26(4):458.

WENHAM C, SMITH J, MORGAN R (2020), "COVID-19: the gendered impacts of the outbreak". The Lancet, Volume 395, Issue 10227, 846 - 848. https://doi.org/10.1016/S0140-6736(20)30526-2

YO SÍ SANIDAD UNIVERSAL (2019), Informe sobre la exclusión sanitaria a un año del RDL 7/2018 sobre "el acceso universal al Sistema Nacional de Salud» [Internet]. Disponible en: https://yosisanidaduniversal.net/materiales/informes/informe-sobre-la-exclusion-sanitaria-un-ano-despues-del-rdl-7-2018 